\title{
IMPLEMENTASI LOGIKA FUZZY DALAM MENGOPTIMALKAN PERSEDIAAN BARANG DENGAN METODE MAMDANI
}

\author{
Azizah $^{1}$, Fauziah $^{2}$ \\ Program Studi Informatika, Universitas Nasional \\ Azizahif99@gmail.com¹, fauziah@civitas.unas.ac.id ${ }^{2}$ \\ Submitted March 8, 2020; Revised June 25, 2020; Accepted July 5, 2020
}

\begin{abstract}
Abstrak
Logika fuzzy dianggap mampu untuk memetakan suatu ruang input ke dalam suatu ruang output. Untuk mengoptimalkan persediaan yang ada pada warung affan dapat menggunakan logika fuzzy dengan metode Mamdani. Penggunaan logika fuzzy diperlukan untuk mengoptimalkan persediaan barang di warung Affan agar persediaan barang tidak berlebih. Metode penelitian menggunakan metode studi literatur dan analisis data dengan tingkat keakuratan data mencapai 83\%. Dari analisis ini dapat mengetahui dan mengoptimalkan persediaan barang pada warung affan dengan metode Mamdani pada bulan januari 2020 mendapatkan keakuratan data 83\% dengan permintaan 1.500 unit, terjual 2.100 unit dan persediaan yang dibutuhkan yaitu 2.300.
\end{abstract}

Kata kunci: matlab, Mamdani, fuzzy, persediaan, optimal.

\begin{abstract}
The fuzzy logic is thought to be able to map an input space into an output space. To optimize the inventory in Affan stalls can use fuzzy logic with Mamdani method. The use of fuzzy logic is necessary to optimize the inventory in Affan stalls to avoid excess items. The study method uses literature study and data analysis with the accuracy of data reaches $83 \%$. From this analysis can know and optimize the inventory of goods in Affan stalls with method Mamdani in January 2020 get the accuracy of the data $83 \%$ with the demand of 1,500 units, sold 2,100 units and supplies required IE 2,300.
\end{abstract}

Keywords: matlab, Mamdani, fuzzy, inventory, optimal.

\section{PENDAHULUAN}

Dewasa ini pergerakan teknologi semakin berkembang dengan pesat dan banyaknya usaha yang hadir. Maka jika ingin berusaha dengan baik harus menggunakan strategi yang matang untuk membuat usaha berkembang.salah satu strategi dengan perancanaan persediaan barang yang bagus dan matang. Warung affan merupakan warung yang mennjual bahan makanan pokok dan makanan ringan seperti gula, beras, kopi dan lainnya. Warung affan memiliki pelanggan lebih dari 100 orang dalam 1 hari nya. Namun pemilik warung affan memiliki masalah seperti berapa banyaknya barang yang dirpoduksi dapat memenuhi kebutuhan pembeli dan agar tidak terbuang dengan sia-sia. Ketersediaan produk dapat menentukan presentase permintaan dan semakin tinggi persediaan barang dagangan, semakin besar stok cadangan [1]. Keuntungan yang maksimal diperoleh dari penjualan yang maksimal. Penjualan yang maksimal artinya dapat memenuhi permintaan-permintaan yang ada. Apabila jumlah produk yang diproduksi oleh perusahaan kurang dari jumlah permintaan maka perusahaan akan ke hilangan peluang untuk mendapatkan keun tungan yang maksimal [2].

Pada pelaku usaha, untuk mengoptimalan persediaan barang akan memberikan pengaruh yang besar, karena selain untuk mengoptimalkan berpengaruh juga pada biaya yang dikeluarkan. Karena dapat memperkirakan pembelanjaan produk, 
biaya transportasi dan penyimpanan. Banyak faktor yang menjadi kendala dalam menentukan persediaan barang. Salah satunya permintaan maksimum dan minimum dalam waktu tertentu. Untuk itulah diperlukan sebuah metode untuk mengatasi masalah tersebut. Logika fuzzy dianggap mampu untuk memetakan suatu ruang input ke dalam suatu ruang output. Logika fuzzy diyakini sangat fleksibel dan memiliki nilai toleransi terhadap data yang ada[3].

Dalam kondisi yang nyata, terdapat beberapa aspek dalam dunia nyata yang selalu atau biasanya berada di luar model matematis dan bersifar inexact.Konsep ketidakpastian inilah yang menjadi konsep dasar munculnya konsep logika fuzzy.Pencetus gagasan logika fuzzy adalah Prof. L. A. Zadeh (1965) dari California University. Pada prinsipnya himpunan fuzzy adalah 93perluasan himpunan crisp, yaitu himpunan yang membagi sekelompok individu ke dalam dua kategori, yaitu anggota dan bukan anggota[4].

Logika fuzzy mamdani merupakan salah satu metode yang sangat fleksibel dan memiliki toleransi pada data yang ada. Fuzzy mamdani memiliki kelebihan yakni, lebih intuitif, diterima oleh banyak pihak. Penggunaan fuzzy mamdani ini sama halnya dengan penggunaan metode peramalan pada bidang statistik[5].

Pada penelitian ini akan digunakan Metode Mamdani untuk menyelesaikan permasalahan jumlah persediaan barang. Metode Mamdani (Min-Max) Untuk metode ini, pada setiap aturan yang berbentuk implikasi ("sebab-akibat") antesenden yang berbentuk konjungsi (AND) mempunyai nilai keanggotaan berbentuk minimum (min), sedangkan konsekuen gabungannnya berbentuk maksimum (max), karena himpunan aturan-aturannya bersifat independent (tidak saling bergantungan)[6].
Kasus persediaan suatu barang pada pelaku usaha bergantung dengan variable yang ada seperti, jenis produk, biaya produk, dan lain-lain. Dalam kasus ini nilai variable tidak dapat diketahui dengan pasti. Himpunan Fuzzy merupakan suatu pengembangan lebih lanjut tentang konsep himpunan dalam matematika. Suatu himpunan fuzzy $\tilde{\mathrm{A}}$ dalam semesta pembicaraan $U$ dinyatakan dengan fungsi keanggotaan, yang nilainya berada dalam interval $[0,1][7]$.

Tujuan dari penelitian ini untuk mengetahui penerapan perhitungan optimal produksi dengan menggunakan logika fuzzy dengan Metode Mamdani. Hasil dari penelitian ini diharapkan agar memberikan manfaat sebagai berikut.

1. Penerapan perhitungan dengan menggunakan Metode Mamdani untuk warung Affan dapat memperkirakan total maksimal persediaan yang harus dikeluarkan setiap bulannya agar dapat memenuhi kebutuhan pembeli dan persediaan tidak berlebih.

2. Sebagai acuan ataupun informasi di bidang industri dalam menentukan jumlah produksi yang optimal.

\section{METODE PENELITIAN}

Penelitian ini dimulai dengan mengumpulkan data dan mempelajari literatur yang dapat mendukung penelitian. Setelah itu dilanjutkan dengan proses analisis data dan kesimpulan.

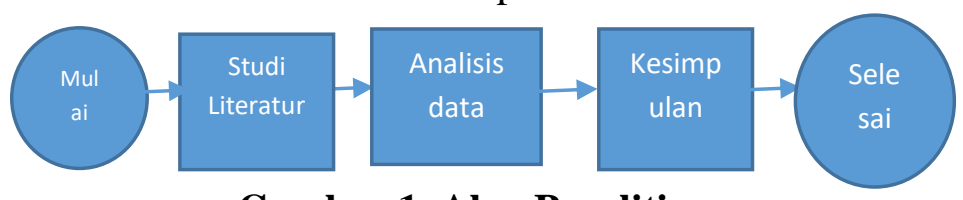

Gambar 1. Alur Penelitian

\section{Studi Literatur}

Metode pengumpulan data pustaka untuk mendapatkan teori yang relevan dengan permasalahan yang diteliti sebagai bahan rujukan dalam pembahasan. 


\section{Analisis data}

Analisis data merupakan pengolahan data yang diperoleh dengan aturan yang sudah ada. Dalam penelitian ini data yang didapat langsung dari warung affan yang akan dianalisis menggunakan Metode Mamdani.

3. Kesimpulan

Dengan menyimpulkan hasil pembahasan yang telah dibahas sebelumnya.

\section{Kebutuhan Sistem}

Untuk menganalisa data penelitian ini menggunakan software Mathlab untuk mendapatkan hasil yang diinginkan.

\section{Kebutuhan Perangkat Lunak User}

Tabel 1. Kebutuhan Perangkat Lunak

\begin{tabular}{ccc}
\hline No & Perangkat Lunak & $\begin{array}{c}\text { Spesifikasi } \\
\text { Minimal }\end{array}$ \\
\hline 1 & Mathlab & Windows 10 \\
\hline
\end{tabular}

\section{Kebutuhan Perangkat Keras User}

Tabel 2. Kebutuhan Perangkat Keras

\begin{tabular}{cll}
\hline No & Perangkat Keras & \multicolumn{1}{c}{ Spesifikasi } \\
\hline 1 & CPU & $1400 \mathrm{Mhz}$ \\
2 & Layar & $540 \times 960 \mathrm{px}$ \\
3 & Memory & $1.5 \mathrm{~Gb}$ \\
4 & Penyimpanan Internal & $8 \mathrm{~Gb}$ \\
\hline
\end{tabular}

\section{HASIL DAN PEMBAHASAN}

Data yang diperoleh dalam penilitian ini berupa produk mie instan dengan data permintaan, persediaan dan produk terjual warung affan dalam periode Agustus 2019 - Desember 2019. Untuk selanjutnya akan ditentukan jumlah persediaan mie instan pada Januari 2020 jika jumlah permintaan sebesar 1.500 unit atau pes dan jumlah persediaan 2.300 unit. Sementara warung affan hanya menyediakan paling banyak 2.500 unit dan paling sedikit 500 unit. Seperti terlihat dalam Tabel 3.
Tabel 3. Data Permintaan dan Persediaan Barang

\begin{tabular}{lllll}
\hline No. & $\begin{array}{l}\text { Periode } \\
\text { Waktu }\end{array}$ & $\begin{array}{l}\text { Permintaan } \\
\text { (unit) }\end{array}$ & $\begin{array}{l}\text { Terjual } \\
\text { (unit) }\end{array}$ & Persediaan \\
\hline 1. & $\begin{array}{l}\text { Agustus } \\
2019\end{array}$ & 500 & 500 & 500 \\
2. & $\begin{array}{l}\text { September } \\
2019\end{array}$ & 800 & 700 & 900 \\
& $\begin{array}{l}\text { Oktober } \\
\text { 2019 }\end{array}$ & 1.000 & 800 & 1.200 \\
November & 650 & 750 & 950 \\
4. & $\begin{array}{l}\text { 2019 } \\
\text { Desember }\end{array}$ & 1.600 & 1.800 & 1.900 \\
5. & $\begin{array}{l}\text { Do19 } \\
\text { Januari }\end{array}$ & 1.500 & 2.100 & 2.300 \\
6. & & & \\
\hline
\end{tabular}

\section{A. Pembentukan Himpunan Fuzzy \\ 1. Fuzzifikasi variable permintaan}

Berdasarkan data permintaan (x) paling banyak yaitu 1.500 dan paling sedikit 500, maka fungsi keanggotaan dirumuskan sebagai berikut.

Tabel 4. Nilai linguistic data permintaan

\begin{tabular}{cc}
\hline Nilai Linguistik & Interval \\
\hline Turun & {$\left[\begin{array}{ll}500 & 1000\end{array}\right]$} \\
Naik & {$\left[\begin{array}{lll}650 & 1600\end{array}\right]$} \\
\hline
\end{tabular}

$\mu_{\text {permintTurun }}(\mathrm{x})$
$=\left\{\begin{array}{c}\frac{1.000-x}{1.000}, \\ 500 \leq x \leq 1.000 \\ x \geq 1.000 \\ 0\end{array}\right.$

$\mu_{\text {permintNaik }}(\mathrm{x})$

$=\left\{\begin{array}{c}\frac{x-650}{1.000}, \quad x \leq 650 \\ 650 \leq x \leq 1.600 \\ x \geq 1.600 \\ 1\end{array}\right.$

Jika diketahui permintaan sebanyak 1.500, maka. 
$\mu_{\text {permintNaik }}(1.500)=\frac{1.500-650}{650}=\frac{850}{650}=1,307$

2. Fuzzifikasi variable produk terjual

Berdasarkan data persediaan (y) paling banyak yaitu 2.100 dan paling sedikit 500, maka fungsi keanggotaan dirumuskan sebagai berikut.

Tabel 5. Nilai Linguistik Data Produk

\begin{tabular}{ll} 
& Terjual \\
\hline Nilai Linguistik & Interval \\
\hline Sedikit & {$[500750]$} \\
Banyak & {$[8002.100]$}
\end{tabular}

$\mu_{\text {terjuaksedikit }}(\mathrm{y})$

$=\left\{\begin{array}{c}\frac{750-y}{750}, \\ 500 \leq y \leq 750 \\ y \geq 750 \\ 0\end{array}\right.$

$\mu_{\text {terjualbanyak }}(y)=\left\{\begin{array}{c}\frac{x-800}{750}, y \leq 800 \\ 800 \leq y \leq 2.100 \\ y \geq 2.100 \\ 1\end{array}\right.$

Jika diketahui produk terjual sebanyak 2.100, maka.

$\mathrm{M}_{\text {terjualbanyak }}(2.100)=\frac{2.100-800}{750}=\frac{1.300}{750}=$ 1,73

\section{Fuzzifikasi variable persediaan}

Berdasarkan data persediaan (z) paling banyak yaitu 2.500 dan paling sedikit 500, maka fungsi keanggotaan dirumuskan sebagai berikut.
Tabel 6. Nilai Linguistik Data Produk Persediaan

\begin{tabular}{ll}
\hline Nilai Linguistik & Interval \\
\hline Berkurang & {$[500900]$} \\
Bertambah & {$[9502.500]$} \\
\hline
\end{tabular}

$\mu_{\text {persedberkurang }}(\mathrm{z})$

$$
=\left\{\begin{array}{c}
\frac{900-x}{900}, \\
500 \leq z \leq 900 \\
z \geq 900 \\
0
\end{array}\right.
$$

$\mu_{\text {persedbertambah }}(\mathrm{z})$

$$
=\left\{\begin{array}{c}
\frac{x-950}{900}, \quad z \leq 950 \\
950 \leq z \leq 2.500 \\
z \geq 2.500 \\
1
\end{array}\right.
$$

Jika diketahui persediaan sebanyak 2.300, maka. $M_{\text {terjualbanyak }}(2.300)=\frac{2.300-900}{900}=\frac{1.400}{900}=$
1,55

\section{B. Komposisi Aturan-Aturan}

Komposisi aturan pada penelitian ini menggunakan metode Max (maximum) yaitu dengan cara mengambil nilai maksimum dari semua aturan.

Tabel 7. Aturan Fuzzy

\begin{tabular}{lllll}
\hline Aturan & $\begin{array}{l}\text { Per } \\
\text { mintaan }\end{array}$ & $\begin{array}{l}\text { Produk } \\
\text { Terjual }\end{array}$ & $\begin{array}{l}\text { F. } \\
\text { Implikasi }\end{array}$ & Persediaan \\
\hline 1 & Turun & Banyak & $\Rightarrow$ & Berkurang \\
2 & Turun & Sedikit & $\Rightarrow$ & Berkurang \\
3 & Naik & Banyak & $\Rightarrow$ & Bertambah \\
4 & Naik & Sedikit & $\Rightarrow$ & Bertambah \\
\hline
\end{tabular}




\section{Defuzzifikasi}

1. Permintaan

Berdasarkan data permintaan (x) 1.500 unit terdapat pada himpunan turun dan naik, maka

$\mu_{\text {permintNaik }}(\mathrm{x})$

$$
=\left\{\begin{array}{c}
\frac{x-650}{1.000}, x \leq 650 \\
650 \leq x \leq 1.600 \\
x \geq 1.600 \\
1
\end{array}\right.
$$

Jika diketahui permintaan sebanyak 1.500, maka.

$\mu_{\text {permintNaik }}(1.500)=\frac{1.500-650}{650}=\frac{850}{650}=1,307$

\section{Produk Terjual}

Berdasarkan data persediaan (y) januari yaitu 2.100 , maka

$\mu_{\text {terjualbanyak }}(y)=\left\{\begin{array}{c}\frac{x-800}{750}, y \leq 800 \\ 800 \leq y \leq 2.100 \\ y \geq 2.100 \\ 1\end{array}\right.$

Jika diketahui produk terjual sebanyak 2.100, maka.

$\mathrm{M}_{\text {terjualbanyak }}(2.100)=\frac{2.100-800}{950}=\frac{1.300}{950}=1,3$

3. Persediaan produk

$\mu_{\text {persedbertambah }}(\mathrm{z})$

$$
=\left\{\begin{array}{c}
\frac{x-950}{900}, z \leq 950 \\
950 \leq z \leq 2.500 \\
z \geq 2.500 \\
1
\end{array}\right.
$$

Jika diketahui persediaan sebanyak 2.300, maka.

$\mathrm{M}_{\text {terjualbanyak }}(2.300)=\frac{2.300-900}{900}=\frac{1.400}{900}=$ 1,55

Dengan demikian didapat nilai sebagai berikut.

Permintaan naik $(1,307)$, Produk terjual naik $(1,3)$ serta persediaan bertambah $(1,55)$.

\section{Penerapan Metode Mamdani Dengan} Matlab

1. Tampilan Variabel input dan output

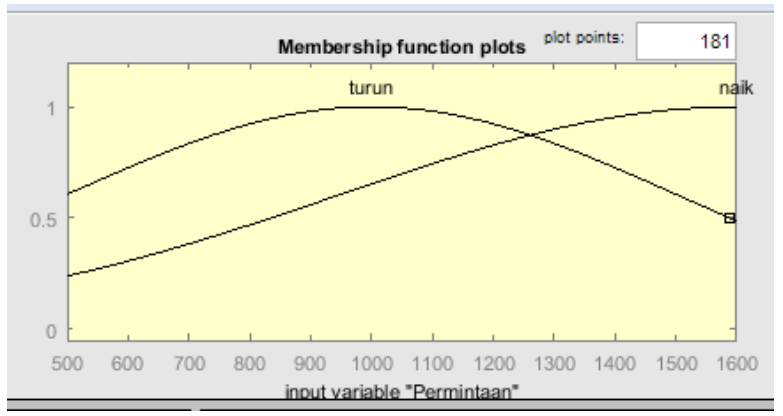

Gambar 2. Variabel Input Permintaan

Gambar 2 merupakan variabel input permintaan dengan variabel naik dan turun.

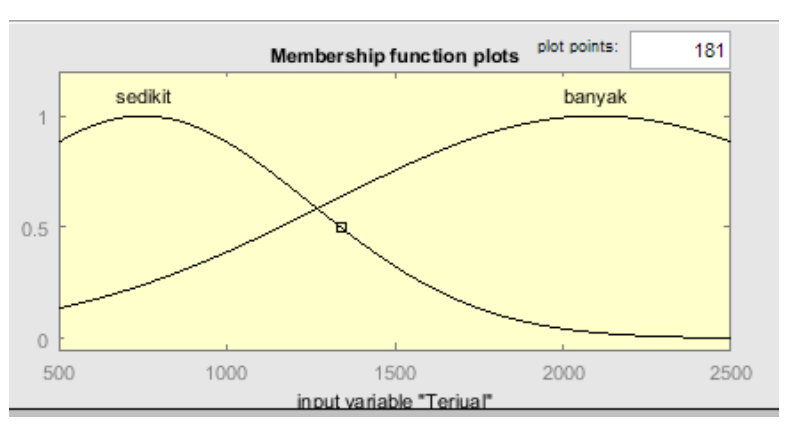

\section{Gambar 3. Variabel Input Produk Terjual}

Gambar 3 merupakan variabel input produk terjual dengan variabel sedikit dan banyak. 


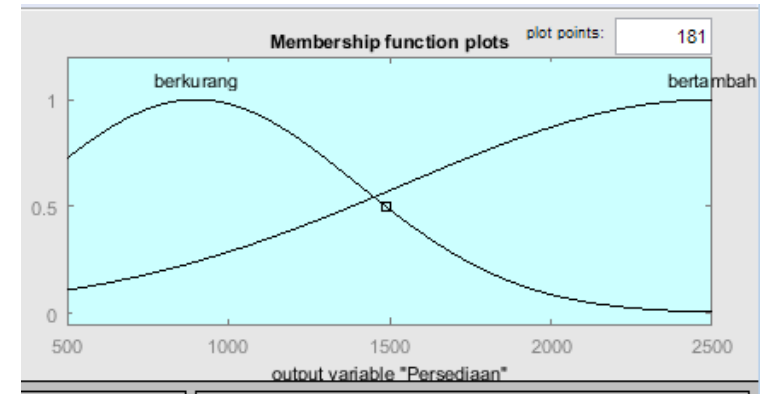

Gambar 4. Variabel Output Persediaan

Gambar 4 merupakan variabel output persediaan dengan variabel berkurang dan bertambah.

\section{Tampilan rules metode Mamdani}

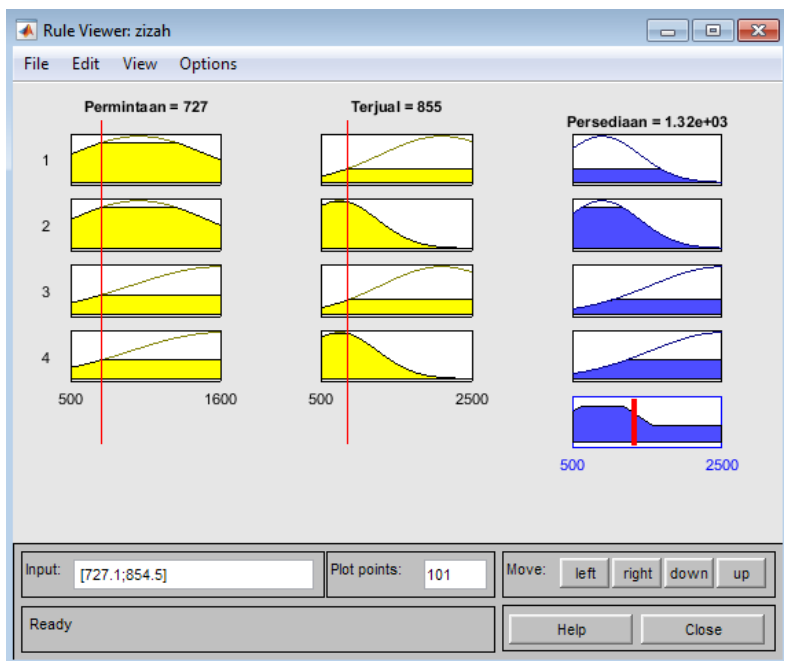

Gambar 5. Rules Metode Mamdani

Gambar 5 didapat dari aturan metode Mamdani yang sudah ditetapkan sebelumnya. Dengan menetapkan aturan metode didapatkan grafik permintaan dengan interval [500 1600], terjual dengan interval [500 2500] dan persediaan dengan interval [500 2500].

\section{Tampilan Diagram}

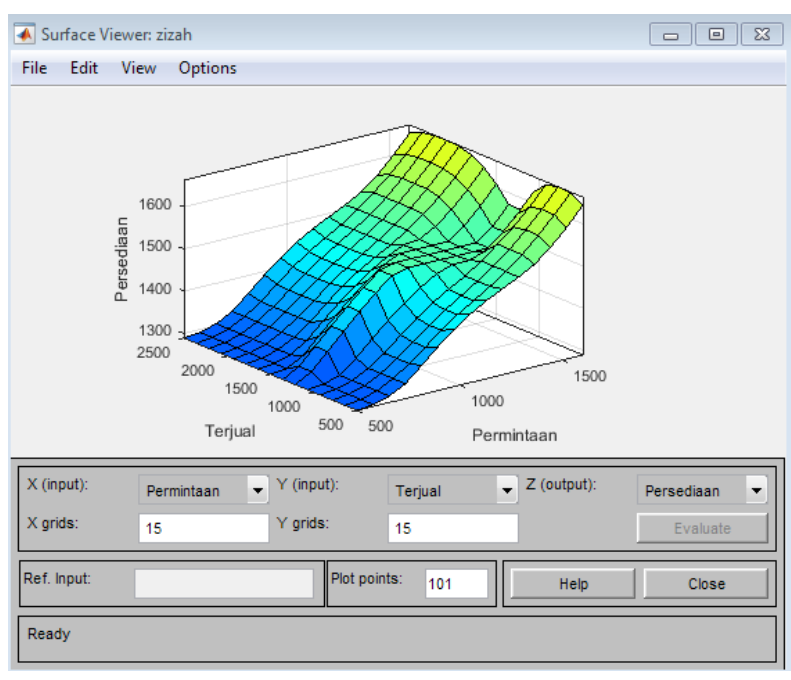

Gambar 6. Tampilan Diagram Hasil Perhitungan

Gambar 6 merupakan tampilan diagram hasil perhitungan dengan nilai interval maksimal persediaan 1600, terjual 2000 dan permintaan sebesar 1500 .

4. Tampilan Hasil defuzzifikasi

a. Permintaan

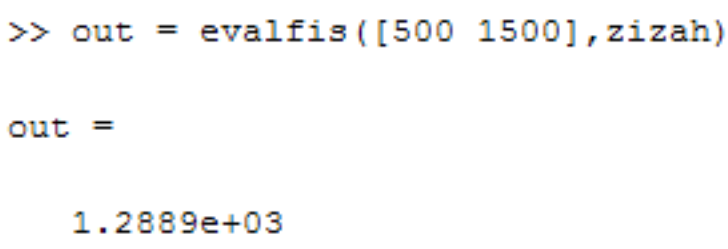

\section{Gambar 7. Hasil dari Defuzzifikasi Permintaan}

Pada gambar 7 mendapatkan hasil 1.2889 sedangkan pada perhitungan manual sebesar 1.307. 
b. Produk terjual

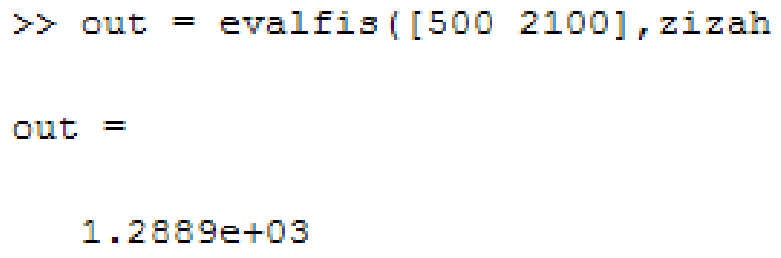

\section{Gambar 8. Hasil Defuzzifikasi Produk Terjual}

Pada gambar 8 mendapatkan hasil 1.2889 sedangkan pada perhitungan manual sebesar 1.3.

c. Persediaan

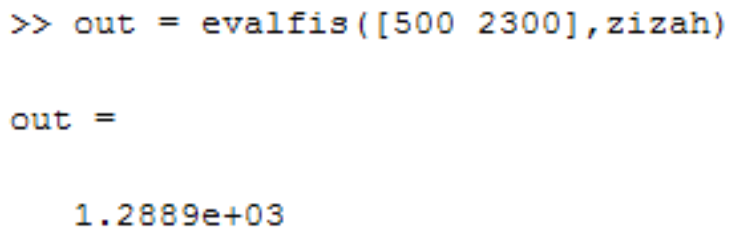

\section{Gambar 9. Hasil defuzzifikasi Persediaan}

Pada gambar 9 mendapatkan hasil sebesar 1.2889 sedangkan perhitungan manual sebesar 1.55.

Dari perhitungan manual yang sudah dikerjakan dengan hasil yang didapatkan menggunakan matlab hasilnya mendekati akurat.

Pengujian model ini menggunakan tingkat keakuratan dari model.

$\begin{array}{ll}\text { Jumlah data benar } & =5 \\ \text { Jumlah data sebenarnya } & =6 \\ \text { Tingkat keakuratan } & =\frac{5}{6} \times 100 \%\end{array}$
$=83,3 \%$

Dalam pengujian secara manual dan menggunakan matlab ada perbedaan hasil defuzzifikasi hanya selisih decimal saja dibulan januari 2020 pada data persediaan.

\section{SIMPULAN}

Penerapan logika fuzzy untuk menentukan jumlah produksi adalah defuzzifikasi yaitu penegasan kembali dari aturan yang sudah ditetapkan. Perhitungan yang dilakukan lebih efektif menggunakan matlab karena lebih cepat tanpa harus menghitung manual kembali.

Berdasarkan analisis persediaan dapat disimpulkan bahwa persediaan barang yang lebih mendekati optimal yaitu yang diperoleh melalui perhitungan menggunakan metode Mamdani. Hasil keakuratan data dilakukan secara manual maupun menggunakan matlab yaitu sebesar $83,3 \%$.

\section{DAFTAR PUSTAKA}

[1] Harefa, Kecitaan. Penerapan Penerapan Fuzzy Inference System Untuk Menentukan Jumlah Pembelian Produk Berdasarkan Data Persediaan dan Penjualan. Jurnal Informatika Universitas Pamulang 205 Vol. 2, No. 4, Desember 2017.

[2] Abrori, Muhammad, dkk. Aplikasi Logika Fuzzy Metode Mamdani Dalam Pengambilan Keputusan Penentuan Jumlah Produksi. Kaunia Vol. XI No. 2, Oktober 2015/1436: 91-99 ISSN 18295266 (print) ISSN 2301-8550 (online).

[3] Harefa, Kecitaan. Penerapan Fuzzy Inference System Untuk Menentukan Jumlah Pembelian Produk Berdasarkan Data Persediaan dan Penjualan. Jurnal Informatika Universitas Pamulang 205 Vol. 2, No. 4, Desember 2017.

[4] Djunaidi, M., Eko S., \& Fajar W.A. 2005. Penentuan Jumlah Produksi dengan Aplikasi Metode FuzzyMamdani. Jurnal Ilmiah Teknik Industri. Vol. 4, No. 2, , 95-104. 
[5] Andani, Sundari Retno. Fuzzy Mamdani Dalam Menentukan Tingkat Keberhasilan Dosen Mengajar. Seminar Nasional Informatika 2013 (semnasIF 2013) ISSN: 1979-2328 UPN "Veteran" Yogyakarta, 18 Mei 2013.
[6] Setiadji. 2009. Himpunan dan Logika Samar serta Aplikasinya. Yogyakarta : Graha Ilmu.

[7] Priyo, Wahyu Toto. Penerapan Logika Fuzzy Dalam Optimasi Produksi Barang Menggunakan Metode Mamdani. Jurnal Ilmiah : SoulMath Vol 5. No. 1, Oktober 2017 